\title{
Acute compartment syndrome of the anterior thigh following quadriceps strain in a footballer
}

\author{
B J Burns, J Sproule, H Smyth
}

Br J Sports Med 2004;38:218-220. doi: 10.1136/bjsm.2003.004762

A rare case is presented of acute anterior compartment syndrome in the thigh of a footballer caused by an acute quadriceps strain, exacerbated by poor first aid and alcohol ingestion. Decompressive fasciotomy with subsequent split skin grafting of the wound defect resulted in a satisfactory outcome. The diagnosis requires a high index of suspicion lest it be overlooked with inevitably disastrous consequences.

A cute anterior compartment syndrome of the thigh in an athlete can be both limb threatening and life threatening and requires urgent diagnosis. The causal factor is usually a blow/direct trauma to the thigh (with or without fracture) or acute muscle overuse. ${ }^{1}$ Other precipitating factors include burns, arterial ischaemia, compression, or intoxication. $^{2}$

\section{CASE REPORT}

A 21 year old man was referred to the emergency department 17 hours after taking part in a club game of soccer, complaining of severe constant pain in his right thigh. He recalled jumping vertically upwards from standing to compete for a header when he experienced acute pain in his right thigh. He denied direct trauma from either the ball or the competing player. He received no attention and continued to play for a further 10 minutes without further incident before limping off the pitch. He received no immediate medical/paramedical attention and did not apply any remedial measures. He consumed about 8 units of alcohol that evening. He took no analgesia.

He was unable to sleep properly, and, after consulting his primary care doctor, presented to the emergency department. He was non-weight bearing on the affected leg.

On examination his right thigh was swollen with a small area of ecchymosis on the anterolateral aspect of the distal thigh. The circumference of the right thigh at a level $10 \mathrm{~cm}$ proximal to the insertion of the quadriceps tendon measured $52 \mathrm{~cm}$ compared with $46 \mathrm{~cm}$ on the left side. His quadriceps muscle was tense and exquisitely tender. Active quadriceps function, as evidenced by his capacity to straight leg raise, was restricted and painful. Passive flexion of his knee was limited by subjective pain. Peripheral pulses were normal and all motor units were intact. There was an area of hypaesthesia in the distribution of the lateral cutaneous nerve of the thigh.

Intracompartmental pressure was measured using a hand held monitoring system (Stryker Surgical, Kalamazoo, Michigan, USA). Anterior compartment pressure measured $29 \mathrm{~mm} \mathrm{Hg}$, medial compartment pressure measured $25 \mathrm{~mm} \mathrm{Hg}$, and posterior compartment pressure measured $27 \mathrm{~mm} \mathrm{Hg}$. Routine blood tests yielded: urea, $3.1 \mathrm{mmol} / \mathrm{l}$; creatinine, $79 \mathrm{mmol} / \mathrm{l} ; \mathrm{K}^{+}, 3.8 \mathrm{mmol} / \mathrm{l} ; \mathrm{Na}^{+}, 136 \mathrm{mmol} / \mathrm{l}$; bicarbonate, $31 \mathrm{mmol} / \mathrm{l}$; white cell count, 10.6; haemoglobin concentration, $109 \mathrm{~g} / \mathrm{l}$; packed cell volume, 0.322. Urinalysis was normal. Radiology confirmed no fracture (figs 1 and 2).

A diagnosis of acute anterior compartment syndrome of the right thigh was made, and the patient gave consent for immediate fasciotomy. The surgical approach was through a lateral skin incision as described by Tarlow et al, ${ }^{3}$ extending from just distal to the intertrochanteric line inferiorly to the lateral epicondyle. The iliotibial band was incised in line with the skin incision. The vastus lateralis immediately herniated through the incision in the iliotibial band. All four muscles of the anterior compartment were considerably oedematous and were released individually. There was a $2 \mathrm{~cm}$ tear in the belly of the rectus femoris. There were no focal collections and no obvious areas of ischaemic or necrotic muscle. The compartment was soft after release. The vastus lateralis was carefully reflected off the lateral intermuscular septum. Releasing the septum along the length of the skin incision decompressed the posterior compartment. The hamstring muscles were normal. The wound was packed open, and sterile dressing was applied. Decompression of the adductor muscles through



Figure 1 Anteroposterior radiograph of lower femur.



Figure 2 Lateral radiograph of lower femur. 
a separate skin incision was deemed not to be indicated. Four days later the defect was covered in theatre by a split skin graft (fig 3), and the patient was immobilised for five days. He did not develop any complications. Rehabilitation entailed initially passive and then gradual active motion exercises. At three months, he was fully mobile and had full range of motion. At five months, he returned to playing soccer.

\section{DISCUSSION}

Richard von Volkmann first described the theory of compartment syndrome in 1881. He described ischaemic palsies and muscle contractures after forearm and supracondylar humeral fractures in children. ${ }^{4}$

In 1926 Jepson showed ischaemia resulting from an increase in pressure in a subfascial space. ${ }^{5}$ However, the definition was finally elucidated in 1976 by Mubarak et al, ${ }^{6}$ who defined the syndrome as "an elevation of the interstitial pressure in a closed osseofascial compartment that results in microvascular compromise"

In a search of the English literature, we could only find two cases of acute thigh compartment syndrome in relation to soccer, and both were related to definite contusion. ${ }^{7}$ To our knowledge this is the only reported case of compartment syndrome following an acute thigh muscle strain. Compartment syndrome of the thigh is, in general, rare possibly because there is a large potential space to allow swelling and hence increase in interstitial pressure before endangering the circulation. ${ }^{8-10}$ Furthermore, the fascial compartments of the thigh blend anatomically with the muscles of the hips, potentially allowing blood to exit the compartment under pressure.

Prompt recognition and surgical intervention in this syndrome are imperative to prevent irreversible ischaemic insult. ${ }^{112}$ In many cases the diagnosis can be made from clinical symptoms and signs alone. The cardinal features are: (a) pain out of proportion to the clinical situation; $(b)$ weakness and pain on passive stretch of the muscles of that compartment; (c) hypaesthesia in the distribution of the nerves running through that compartment; $(d)$ tenseness of the fascial envelope surrounding the compartment. ${ }^{13}{ }^{14}$

Close monitoring of the limb at heart level and regular examination of the patient at risk is essential once it has been decided that there is the possibility of compartment syndrome. If the above symptoms and signs worsen or do not resolve, then prompt fasciotomy is indicated. However, clinical findings may be equivocal if the patient has a head injury with a lowered Glasgow coma score causing a lack of communication. Furthermore, spinal cord injury and peripheral nerve injury may cloud the issue, as will the uncooperative patient. In these cases, the clinician may not rely on examination alone and involve scientific compartmental pressure monitoring.



Figure 3 Fasciotomy with split skin graft in situ.

\section{Pressure monitoring}

The normal intracompartmental pressure ranges between 0 and $8 \mathrm{~mm} \mathrm{Hg} .{ }^{16}{ }^{16}$ Gelberman et al ${ }^{17}$ suggested that ischaemia of muscles and nerves occurs at about $30 \mathrm{~mm} \mathrm{Hg} .{ }^{17}$

Matsen et $a l^{18}$ used Whiteside's continuous pressure monitoring by way of an infusion technique catheter. Although there may be a role for this method in the settings mentioned above, we feel this may cause the clinician to misleadingly rely on this method alone. Matsen et al observed that, with this technique, there was a large range of intracompartmental pressures in which some alert patients developed neuromuscular deficits while others did not. They showed that all patients who had maximum intracompartmental pressures of $45 \mathrm{~mm} \mathrm{Hg}$ did not require fasciotomy. All patients with maximum intracompartmental pressures of $55 \mathrm{~mm} \mathrm{Hg}$ displayed the signs and symptoms of compartment syndrome. Importantly, they showed variability in pressure tolerance of a limb depending on its position relative to the heart. ${ }^{19}$

Schwartz et $a l^{10}$ reported on a series of 21 thigh compartment syndromes in 17 patients referred to their trauma centre. They considered pressures of $30-40 \mathrm{~mm} \mathrm{Hg}$ potentially critical for the development of myoneural necrosis. A pressure exceeding $40 \mathrm{~mm} \mathrm{Hg}$ was considered diagnostic. Thus there is obviously a low sensitivity and specificity attached to intracompartmental pressure monitoring.

\section{Nerve stimulation}

Direct nerve stimulation may be used when one is trying to ascertain why the patient is unable to voluntarily contract the muscles of a compartment. Is this because of the compartment pressures causing neuropraxia or primary nerve injury proximal to the compartment? This is useful in the patient with proximal nerve injury, spinal cord injury, and head injury. This can be done at the bedside with a hand held nerve stimulator such as the NS-2A peripheral nerve stimulator (Professional Instruments Company, Houston, Texas, USA). The electrical impulse is given subcutaneously in approximation to where the nerve in question enters the compartment. Failure of the muscle to contract would suggest myoneural necrosis and hence compartment syndrome. However, if the muscle produces a normal response to stimulation, it can be concluded that there is a nerve injury proximal to the compartment. This is not useful as a prospective monitoring aid, as clinical grounds should preempt the development of paralysis secondary to compartment syndrome. We believe this form of investigation is open to operator disparity caused by incorrect placement of the stimulation needles. Furthermore, in severe trauma it is possible to have concomitant acute nerve injury to a compartment and compartment syndrome, thus rendering this investigation unhelpful.

Our patient represents that small group of patients in whom compartment syndrome develops insidiously. Although this patient cannot recall blunt trauma to the thigh, it is possible that he did in fact sustain direct trauma, as evidenced by the ecchymosis and swelling. However, there is also the possibility that the pathophysiology was related to an acute strain of the quadriceps muscle causing muscle oedema secondary to inflammation. Oedema is usually proportional to muscle damage. ${ }^{20}$ The mechanism of injury and lack of recall of trauma would support this. Furthermore, this patient took no measures to lessen the swelling and in fact aggravated it by not maintaining the leg at heart level and consuming alcohol. Alcohol has a clear association with increasing oedema.

There have been a few reports of compartment syndrome occurring after intense exercise. We do not associate this patient's case with compartment syndrome related to intense 
exercise. Nau et $a^{21}$ described such a case in the right thigh of a 51 year old man which developed three days after intensive weight training. This patient had gross muscle oedema visualised after fasciotomy and raised creatine kinase ( $1800 \mathrm{U} / \mathrm{l})$ and lactate dehydrogenase (411 U/1) activities, indicating muscle damage. Kahan et $a^{22}$ described a similar case in a 27 year old man who presented with reddish/brown urine, fever, and cramping pain in his thighs. He had performed 200 squats 24 hours before in response to a challenge and was not used to high intensity endurance exercise. His creatine kinase (116 $460 \mathrm{U} / \mathrm{l})$ and lactate dehydrogenase $(4230 \mathrm{U} / \mathrm{l})$ activities were grossly elevated. Intracompartmental pressures confirmed bilateral compartment syndrome. Bilateral fasciotomies were performed and necrotic muscle was debrided. Reneman ${ }^{23}$ described a series of 52 patients who had acute compartment syndrome caused by intensive use of the leg muscles. He postulated that the primary contributing factor causing the increase in intramuscular pressure (hence compartment pressure) was acute muscle hypertrophy. He proposed that there was a $20 \%$ increase in muscle volume caused by an increase in transcapillary filtration resulting from an increase in capillary pressure and surface area not compensated for by drainage.

\section{Conclusion}

We conclude that our patient developed an acute quadriceps strain causing inflammation and oedema in the muscle. This common and usually non-threatening injury developed into a compartment syndrome because of increased capillary pressure and increased surface area secondary to acute muscle strain, aggravated by the vasodilatory effects of alcohol, coupled with the effect of gravity to decrease venous return. Inappropriate immediate measures for decreasing swelling and actions that aggravate swelling of an injury can result in a potentially life threatening event. Compartment pressure measurements should only be used as a helpful guide in what is essentially, in the majority of instances, a clinical diagnosis. The clinician must remain vigilant and maintain a high index of suspicion lest an acute compartment syndrome be overlooked with inevitably disastrous consequences.

\section{Authors' affiliations}

B J Burns, Emergency Department, St Vincent's University Hospital, Dublin, Republic of Ireland

J A Sproule, H Smyth, Department of Orthopaedic and Trauma Surgery, St James's Hospital, Dublin, Republic of Ireland
Correspondence to: Dr Burns, Emergency Department, St Vincent's Hospital, Elm Park, Dublin 4, Republic of Ireland or 52 Beechpark Drive, Foxrock, Dublin 18, Republic of Ireland; bburns_2000@yahoo.com

Accepted 11 February 2003

\section{REFERENCES}

1 Bidwell JO, Gibbons CER, Godsiff S. Acute compartment syndrome of the thigh after weight training [case report]. Br J Sports Med 1996;30:264-5.

2 Florkowski CM, Rossi ML, Carey MP, et al. Rhabdomyolysis and acute renal failure following carbon monoxide poisoning: two case reports with muscle histopathology and enzyme activities. J Toxicol Clin Toxicol 1992;30:443-54.

3 Tarlow SD, Achterman CA, HayhurstJohn, et al. Acute compartment syndrome in the thigh complicating fracture of the femur. A report of three cases. J Bone Joint Surg [Am] 1986;68:1439-43.

4 Von Volkmann R. Die ischämische Muskellähmungen and Kontrakturen. Zentralb/ Chir 1881;8:801-3.

5 Jepson PN. Ischemic contracture: an experimental study. Ann Surg 1926;84:785-95.

6 Mubarak SJ, Hargens AR, Owen CA, et al. The Wick catheter technique for measurement of intramuscular pressure. A new research and clinical tool. $J$ Bone Joint Surg [Am] 1976;58:1016-20.

7 Robinson D, On E, Halperin N. Anterior compartment syndrome of the thigh in athletes: indications for conservative treatment. J Trauma 1992;32:183-6.

8 Colosimo AJ, Ireland ML. Thigh compartment syndrome in a football athlete: a case report and review of the literature. Med Sci Sports Exerc 1992;24:958-63.

9 Mubarak SJ, Hargens AR. Compartmental syndromes and Volkmann's Contracture. Philadelphia: WB Saunders, 1981:127-9, 160-1.

10 Schwartz JT, Brumback RJ, Lakatos R, et al. Acute compartment syndrome of the thigh. A spectrum of injury. J Bone Joint Surg [Am] 1989:71:392-400.

11 Matsen FA III, Winquist RA, Krugmire RB. Diagnosis and management of compartmental syndromes. J Bone Joint Surg [Am] 1980;62:286-91.

12 Sheridan GW, Matsen FA III. Fasciotomy in the treatment of acute compartment syndrome J Bone and Joint Surg [Am] 1976;58:112-15.

13 Matsen FA III. Compartmental syndrome. A unified concept. Clin Orthop 1975; 113:8-14.

14 Matsen FA III, Krugmire RB. Compartmental syndromes. Surg Gynecol Obstet 1978; 147:943-9

15 Lee BY, Brancato RF, Park ICH, et al. Management of compartmental syndrome. Diagnostic and surgical considerations. Am J Surg 1984; 148:383-8.

16 Whitesides TE, Haney TC, Morimoto K, et al. Tissue pressure measurements as a determinant for the need of fasciotomy. Clin Orthop 1975;113:43-51

17 Gelberman RH, Szabo RM, Williamson RV, et al. Tissue pressure threshold for peripheral nerve viability. Clin Orthop 1983;178:285-91.

18 Matsen FA III, Winquist RA, et al. Diagnosis and management of compartmental syndromes. J Bone Joint Surg [Am] 1980;62:286-91.

19 Matsen FA III. Compartmental syndromes. New York: Grune and Stratton, in press.

20 Whitesides TE, Heckman MM. Acute compartment syndrome: update on diagnosis and treatment. J Am Acad Orthop Surg 1996;4:209-18.

21 NauThomas, Menth-Chiari WA, SeitzHelmut, et al. Acute compartment syndrome of the thigh associated with exercise. Am J Sports Med 2000;28:120-2.

22 Kahan JS, McClellan R, et al. Acute bilateral compartment syndrome of the thigh induced by exercise. A case report J Bone Joint Surg [Am] 1994:76:1068-71.

23 Reneman RS. The anterior and lateral compartment syndrome from anterior thigh muscle contusion: a report of eight cases. Clin Orthop 1975;113:69-80. 